\section{Claudia Comes Peña}

Claudia Comes Peña es Profesora asociada en la Universidad de Alicante. Ha trabajado como lectora de español en la Universidad Heinrich Heine de Düsseldorf (Alemania) y en el centro de idiomas de la Universitat Pompeu Fabra de Barcelona. Ha publicado diversos artículos dedicados a la literatura colonial, con especial atención al siglo XVIII mexicano, tema sobre el que realiza su tesis doctoral.

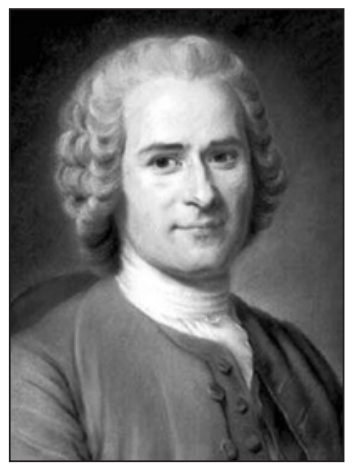

Retrato de Jean-Jacques Rousseau
Feijoo y la Ilustración en una polémica novohispana del siglo XVIII: ¿Es Eguiara y Eguren un escolástico ilustrado?

\title{
FEIJOO Y LA ILUSTRACIÓN EN UNA POLÉMICA NOVOHISPANA DEL SIGLO XVIII: iES EGUIARA Y EGUREN UN ESCOLÁSTICO ILUSTRADO?
}

\author{
CLAUDIA COMES PEÑA \\ Universidad de Alicante \\ claudia.comes@ua.es
}

\section{RESUMEN}

En este artículo vamos a analizar el significado y la finalidad que adquieren las menciones a autores ilustrados como Feijoo en el contexto de una polémica sobre la valía intelectual de los americanos desarrollada en la Nueva España del siglo XVIII. Como veremos, las citas no nos permiten afirmar que se dé una asimilación de las nuevas ideas, sino que son utilizadas para demostrar el conocimiento que se tiene de estas en los territorios americanos, una muestra de que están al día de las novedades europeas, convirtiéndose en un argumento apologético más en el marco de una polémica.

Palabras clave: Eguiara y Eguren, Ilustración, Feijoo, escolasticismo, Nueva España.

\section{ABSTRACT}

In this paper we will analyze the meaning and the objective that the references to enlightened authors as Feijoo acquire in the context of a debate about the intellectual prowess of the Americans developed in Eighteenth-Century New Spain. The quotes don't show that an assimilation of new ideas exist, but these new ideas are used to demonstrate the knowledge about the Enlightenment in the American territories, a sample of americans intellectuals are up to date with European developments, becoming a more apologetic argument in the context of a controversy.

Keywords: Eguiara y Eguren, Enlightenment, Feijoo, scholasticism, New Spain.

Se ha escrito mucho sobre las características del movimiento ilustrado en el ámbito de la América colonial, llegando incluso a poner en cuestión su mera existencia. Como ha señalado Robert Darnton (2003, p. 15 y ss.), las adjetivaciones al término han sido abundantísimas tanto en Europa como al otro lado del Atlántico. Este hecho da buena cuenta de las diferentes características que, según los críticos, adoptó lo que en esencia y en un sentido muy laxo del término podríamos considerar una amplia corriente de pensamiento renova- dor que tuvo su origen en la Europa de finales del siglo XVII.

En el caso hispanoamericano la cuestión se hace aún más compleja por diversos factores. En primer lugar, el debate habitualmente ha girado en torno al problema de las «fuentes», a si se pueden encontrar rastros de la presencia del pensamiento ilustrado europeo en los autores americanos, como ha señalado, entre otros José Carlos Chiaramonte (1979, p. XIII). A este respecto, encontramos posturas tan distantes como la de Germán Arciniegas, 
para quien la presencia de Descartes como precursor y de Rousseau como ideólogo principal son totalmente indiscutibles: «De todos los autores de la época ninguno agitó tanto el mundo hispánico como Rousseau [...] El punto central iba a ser El contrato social. Se publicó en 1762. Se difunde en América con tal rapidez y extensión que ya antes de 1780 no solo lo conocen los literatos, sino también el pueblo» (1956, p. 43). El polo opuesto lo representaría François López, para quien la Ilustración hispanoamericana fue «tardía y débil» así como «frágil y moderada» (1979, p. 292). Aunque es indudable la presencia de autores ilustrados franceses en la América colonial del XVIII, como se desprende de los trabajos de José Carlos Rovira (1999) sobre la inquisición novohispana, otra cuestión muy diferente sería dilucidar qué tipo de desarrollo tuvieron estas ideas y de qué manera se adaptaron al desarrollo intelectual hispanoamericano.

El segundo aspecto que se debe abordar al tratar la Ilustración iberoamericana está íntimamente relacionado con este primero, hasta el punto de que muchas ocasiones llega a solaparse con él y resulta complicado desentrañar ambas cuestiones. Se trata de la relación entre Ilustración e Independencias. La crítica, ya en el siglo XIX, estableció entre estos dos elementos una relación de causalidad según la cual la presencia de este pensamiento sería el que generó la separación de los llamados «reinos de Ultramar» y su configuración como naciones independientes. Tanto se ha fijado el foco en los procesos de finales de siglo que incluso se llegó a afirmar que la debilidad de la presencia ilustrada explicaría la -supuesta- debilidad contradictoria de los movimientos independentistas del siglo XVIII o incluso su carácter prematuro (López, 1979). «El resultado fue una historia del pensamiento de la Ilustración como historia de la Independencia y sus antecedentes; una historia, entonces, con escasos matices, ciertas exageraciones y muchos olvidos» (Chiaramonte, 1979, pp.XI-XII).

La forma de abordar esta cuestión ha tenido, como acertadamente resumen Diana Soto Arango et alt., entre otros, dos enfoques contrapuestos: «a partir de la Independencia nace la historiografía colonial y, con esta, dos tendencias en marcada contradicción: la liberal-nacionalista y la conservadora-hispanista» (1995, pp. 9-10). La primera, obviamente, se ha convertido en una corriente historiográfica preocupada por rescatar los rastros «ilustra- dos» de procedencia fundamentalmente francesa asociados a los criollos para contraponerlos a una supuesta mentalidad conservadora encarnada por la Metrópoli y sus representantes. La segunda sostenía que el pensamiento ilustrado era de procedencia española y se debió, sobre todo, al influjo de la iglesia católica. A partir de los años 70 del siglo XX también se desarrolló una tercera tendencia, alejada de los dos extremos anteriores y con un planteamiento de base diferente, en el marco de la cual se pretendía «sustraer el fenómeno emancipador de los estrictos factores ideológicos y devolvérselo, en su lugar, a la acción mucho más difusa de las circunstancias» (San José, 2006, p. 284).

No es mi propósito abordar aquí una tarea de definición que desbordaría los límites de un artículo y mis capacidades, pero creo que estas disquisiciones son necesarias para abordar cabalmente el tema planteado. En las páginas que siguen, por lo tanto, vamos a intentar trazar un panorama de los elementos a los que se creyó conveniente recurrir para elaborar una argumentación convincente en un lugar y momento dados, y con un objetivo determinado. En otras palabras, vamos a rastrear la presencia de un ilustrado peninsular, el padre Feijoo, en Nueva España en un contexto muy concreto: la respuesta apologética que dio Juan José de Eguiara y Eguren en su Bibliotheca Mexicana (1755) a una carta escrita por el deán de Alicante Manuel Martí y publicada en 1735 en la que se criticaba el bajo nivel cultural de las tierras americanas. Su cita se hace recurrente en la polémica que se desató y vamos a intentar desentrañar si esta lectura del benedictino implicaba también una asimilación de sus postulados renovadores. ¿Significa que podemos contar a Eguiara entre los ilustrados americanos? ¿Qué postura adopta frente a las ideas ilustradas que cita? ¿Encontramos aquí y en fechas tan tempranas esa vinculación entre ilustración e independencia?

Responder a estas preguntas nos permitirá acercarnos al juego dialéctico sobre el que realmente se va conformando la vida cultural y el pensamiento de una determinada época y lugar. Para ganar en profundidad y exactitud
Manuel Martí, deán de Alicante. Grabado de Palomino
Feijoo y la Ilustración en una polémica novohispana del siglo XVIII: ¿Es Eguiara y Eguren un escolástico ilustrado?

CLAUDIA COMES PEÑA 
Sobre este tema sigue siendo fundamental el trabajo de Agustín Millares Carlo (1944).

Utilizo el término acuñado por Edmundo O'Gorman (1942), Fundamentos de la historia de América, México, Imprenta Universitaria. Con él se refiere a la oleada de opiniones peyorativas de algunos ilustrados europeos en relación a América y sus habitantes.

Feijoo y la Ilustración en una polémica novohispana del siglo XVIII: ¿Es Eguiara y Eguren un escolástico ilustrado?

CLAUDIA COMES PEÑA es preferible, por lo tanto, hablar de procesos con tendencias dominantes en lugar de definiciones, más aún si cabe, cuando nos acercamos al complejo mundo intelectual novohispano, ya que «la vida espiritual de este siglo es mucho más dialéctica y transcurre en direcciones más contrapuestas a las que dejan ver» (Sánchez Blanco, 1991, p. 14) las definiciones tradicionales.

\section{Las reflexiones de Feijoo sobre América}

Como han destacado Vicente Palacio Atard (1966) o José Antonio Maravall, «en América, Feijoo ocupa la misma posición y desempeña el mismo papel que en la Península. Es leído e influye como ningún otro en el pensamiento del siglo XVIII y el carácter polémico de su obra es paralelo a ambos lados del Océano, dando lugar a campañas semejantes y trayendo consecuencias similares a la penetración del pensamiento moderno» (1991, p. 349). Sin embargo, la relevancia de su figura cobra un nuevo sentido por la relación directa de algunos de sus escritos con las tierras americanas y sus habitantes ${ }^{1}$ en el marco de lo que se ha dado en llamar la «calumnia de América»².

Sus reflexiones abarcan desde disquisiciones a propósito de cómo llegaron al continente los indios («Solución al gran problema histórico sobre la población de América y revoluciones del globo terráqueo», Discurso 15 del tomo $\mathrm{V}$ del Teatro crítico) hasta los «errores comunes» que afectan a la capacidad intelectual de sus habitantes, incluso los de origen europeo. Y es precisamente este último caso el que más despertó la admiración de los americanos y provocó una oleada de alabanzas y agradecimientos hacia su figura entre los criollos.

Son dos los discursos del Teatro crítico que calaron con fuerza entre los habitantes de América, independientemente de si comulgaban o no con el resto de ideas científicofilosóficas del benedictino. Se trata de «Mapa intelectual y cotejo de naciones» (discurso 15 del tomo II, 1928) y, sobre todo, de «Españoles americanos» (discurso 6, tomo IV, 1930).

En el primero, afirma que el 'ingenio' de los hombres está equitativamente distribuido en todas las regiones del planeta, con lo que se coloca en contra de la "común opinión» según la cual hay naciones sabias, naciones silvestres y naciones estúpidas: «por lo que mira a lo substancial tengo por casi imperceptible la desigualdad que hai de unas Naciones a otras en orden al uso del discurso» (Feijoo, 1779 , p. 303). Después del análisis que realiza a partir de diversos ejemplos llega a la conclusión de que el problema no es la falta de ingenio o dotes naturales, sino la falta de estudio y aplicación. Sin embargo, cuando llega el momento de hablar del caso concreto de los americanos, reproduce una idea muy extendida en la época:

Muchos han observado que los Criollos, o hijos de españoles, que nacen en aquella tierra, son de más viveza, o agilidad intelectual, que los que produce España, lo que añaden otros, que aquellos ingenios, assí como amanecen más temprano, también se anochece más presto; no sé que esté justificado (Feijoo, 1779, p. 314).

Aunque reproduce el prejuicio, es significativo que remarque al final que no ha podido contrastar su veracidad, hecho que la deja en suspenso y que después le dará pie para retomar el tema en un artículo posterior.

Hacia el final del artículo da como origen de estas ideas deterministas sobre el clima a las teorías de Aristóteles, a quien él mismo rebate con algunos ejemplos. Este elemento de ataque a las teorías aristotélicas tendrá su importancia en la recepción de estas ideas que efectuarán los americanos implicados en la polémica, como veremos más adelante.

El segundo artículo que debemos tratar, «Españoles americanos» es, sin duda, el que mayor eco tuvo en el ámbito que tratamos. En él vuelve sobre lo dicho en el discurso que acabamos de resumir para rectificar la afirmación que había dejado en suspenso y corregirla:

Un Cavallero de ilustre sangre [...] me avisó, que esta opinión común debía comprehenderse entre los errores comunes. [En este discurso] pretendo desterrar una opinión tan injuriosa a tantos españoles que la transmigración de sus padres, o avuelos hizo nacer debaxo del Cielo Americano (Feijoo, 1775, p. 110).

Feijoo, siguiendo su método habitual para desenmascarar los errores comunes, procede a analizar el caso y detecta su origen en el sistema de estudios: si se parte de que todas las personas tienen las mismas capacidades, tal como había afirmado en «Mapa intelec- 
tual...», el supuesto adelanto de los americanos se da porque los estudiantes se inician antes en las letras y llevan a cabo el estudio de una forma mucho más intensiva:

Sábese que en la América por lo común a los doce años, y muchas veces antes, acaban de estudiar los niños la Gramática, y Retórica, y a proporción en años muy jóvenes se gradúan en las Facultades mayores. De aquí se ha inferido la anticipación de su discurso; siendo así, que este adelantamiento se debe únicamente al mayor cuidado que hay en su instrucción, y mayor trabajo a que los obligan; y proporcionalmente en los estudios mayores sucede lo mismo. Acostúmbrase por allá poner a estudiar los niños en una edad muy tierna. [...] Juntas todas las vacaciones que hay entre año, sólo componen un mes; por lo cual en dos años solos absuelven toda la Filosofía; pero echada la cuenta, según la práctica de las Universidades de España, que en cada año tienen casi seis meses de vacación, mayor porción de tiempo dan al estudio de la Filosofía allá que acá. [...] Con que bien mirado todo el aprovechamiento anticipado de los criollos en ellas no se debe a la anticipación de su capacidad, sí a la anticipación de estudio y continua aplicación en él (Feijoo, 1775, pp. 117-118).

Finaliza esta parte del discurso con una larga lista de personalidades que, desde la experiencia, han hablado del ingenio de los criollos y de otros que, incluso sin haber visitado América, se han hecho eco de esos elogios. Feijoo destaca que ninguno de ellos menciona la segunda parte del «error común», es decir, la supuesta temprana decrepitud del ingenio. Nuevamente busca una causa racional para tal afirmación y la encuentra en una de tipo sociológico que había recogido en su libro Antonio Peralta Castañeda: no es que los ingenios decaigan pronto sino que permanecen poco 'en activo' porque el estudio no les proporciona las recompensas esperadas y deben ganarse la vida mediante otras tareas. «Esto ha ocasionado el error común que impugnamos, interpretándose en decadencia de la capacidad lo que es abandono de la aplicación» (Feijoo, 1775 , p. 124). Con este discurso veían los americanos defendida su honorabilidad intelectual por la mano de una de las personalidades más relevantes del momento.

Rastros de la presencia de Feijoo en América los encontramos desde fechas muy tempranas (Millares, 1944, p. 157; Cruz, 1966, p. 48). Sin ir más lejos, en la aprobación del tomo sexto del Teatro crítico (1734) José
Mariano Gregorio de Elizalde Ita y Parra, el que fuera rector de la universidad de México y padrino de Eguiara y Eguren en su acceso al Cabildo Catedralicio, al hablar de la fama del asturiano dice que no se reduce a España o Europa «sino que extendiéndose hasta los distantísimos términos de la América, en ambos reynos, y de la Asia $\mathrm{y}$ en las Filipinas, disfrutan sus individuos el gozar de su hermosura» (Millares, 1944, ibid.).

\section{La polémica mexicana: argumen- tos y protagonistas}

Pasemos ahora a resumir brevemente las características de la polémica a la que nos referimos ${ }^{3}$. En 1735 aparecieron editados en Madrid dos volúmenes de epístolas que reunían la correspondencia latina del humanista Manuel Martí, por entonces deán de la catedral de Alicante. La recepción americana se centró fundamentalmente en una de las cartas, la número $16 \mathrm{del}$ libro VII. En ella, como es bien sabido, Martí intenta disuadir a un discípulo suyo, Antonio Carrillo, de que se traslade a América, tierra que Martí presenta como modelo de incultura y dejadez intelectual, lo que inevitablemente desencadenó la legítima furia de los mexicanos y cientos de páginas como alegato de defensa. El deán de Alicante se convirtió entonces -y así ha continuado hasta nuestros días ${ }^{4}$ - en paradigma de la ignorancia sin límites, cuando no de la mala fe, de los europeos en lo tocante a las cosas del Nuevo Mundo. Lo explícito del ataque deja poco margen a matizaciones en lo que al enunciado se refiere:

¿A quién acudirás, no diré ya a un maestro, con cuyos consejos puedas instruirte, sino simplemente a alguien que te escuche? No diré a un sabio, sino a alguien deseoso de saber. Te lo diré más claro: alguien que no aborrezca las letras. ¿Qué libros abrirás? ¿Qué bibliotecas examinarás? Intentarás conseguir esto tan inútilmente como el que esquila un burro o el que ordeña un macho cabrío (Martí, 1735, vol. II, p. 36).

Mientras que en la Península Ibérica las líneas hiperbólicas de Martí referentes a América pasaron prácticamente inadvertidas, sí que fueron tomadas muy en serio al otro lado del
THEATRO RITICO UNIVERSAL, DISCURSOS VARIOS,

TODO GENERO DE MATERIAS, PARA DESENGANO

E ERRORES COMUNES,

DE D I C A D O

$L$ R - P. M. Fr. JOSEPH DE

nuevo, General de la Congregacion de

San Benito de E/paña, Inglaterra,

E S C R IT O

R EL M.R.P.M. FF. BENITO GARONIMO FEYYOO

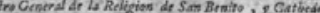

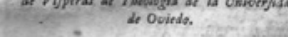

TOMO PRIMERO.

SEGUNDA IMPRESSION.

CON PRIVIKEGIO

Aiso de M, D

Portada del Theatro crítico universal de Feijoo

3

Un buen resumen de la misma se puede encontrar en el artículo de José Carlos Rovira (1995), así como en el «Prólogo» de Ernesto de la Torre Villar (1989).

Tanto Agustín Millares Carlo como Ernesto de la Torre Villar siguen en sus respectivas ediciones de los Anteloquia la interpretación dada por Eguiara. Sólo en el trabajo de Ignacio Osorio Romero, Conquistar el eco. La paradoja de la conciencia criolla se hace un intento de enmarcar la epístola de Martí en su contexto de enunciación: "Creo que los modernos no hemos sabido matizar el juicio de Martí y nos hemos dejado influir por la opinión acrítica de sus contemporáneos. Es cierto, la carta contiene frases e imágenes ofensivas para los novohispanos y el rechazo vehemente que los novohispanos de ellas hacen es justo; pero también el juicio de Martí se inscribe en un contexto más amplio: la valoración que Martí hace de la cultura de España $y$, por consiguiente, de la de sus colonias» (1989, p. 44).

Feijoo y la Ilustración en una polémica novohispana del siglo XVIII: ¿Es Eguiara y Eguren un escolástico ilustrado?

CLAUDIA COMES PEÑA 
Atlántico: las reacciones ante una descripción tan despectiva y sombría del panorama intelectual americano no se hicieron esperar. $\mathrm{La}$ avalancha de réplicas que se dieron a partir de 1744 nos permite fijar con bastante precisión el momento de la recepción. Entre las doce respuestas explícitas a Martí que hemos localizado, escritas entre 1744 y 1761, se pueden distinguir tres grupos.

El primero reúne las réplicas realizadas entre Ciudad de México y Puebla de los Ángeles, los dos grandes focos culturales de la Nueva España. Además del criterio geográfico, las vinculan dos elementos más: la inmediatez respecto a la recepción de la epístola y su brevedad, ya que tratan el tema casi como un añadido sin demasiada relación -o solo tangencial- con el contenido de las obras en que se insertan. Además, la característica más sobresaliente es que en ellas solo se impugna lo que el alicantino dijo contra las virtudes morales e intelectuales de los habitantes de origen español afincados en Indias, los criollos. En ninguno de ellos encontramos rastros de una defensa de las cualidades de los españoles en general ni de la población indígena que tan malparada aparecía en la epístola de marras. El segundo grupo está formado por dos respuestas que, si bien comparten este último rasgo con el anterior, fueron realizadas fuera del territorio novohispano, concretamente en Cuba y Quito, por lo que dan cuenta de la amplitud geográfica que tuvo la reacción. El último grupo comprende en realidad una sola obra, pero que por su importancia y singularidad requiere un tratamiento específico. Se trata de la Bibliotheca Mexicana (1755) de Juan José de Eguiara y Eguren, el primer catálogo biobibliográfico que recopila, de manera apologética, el nombre y las obras de más de dos mil autores que habían escrito en Nueva España. Es en el prólogo a esta obra, dividido en veinte capítulos o anteloquia, en el que se impugnan las afirmaciones del deán de Alicante. $Y$ es también aquí donde se hace mención a la figura de Feijoo.

\section{Feijoo en los Prólogos de Eguiara y Eguren}

La elección de la obra de Eguiara y Eguren como modelo del tratamiento que se hizo de los escritos de Feijoo en el contexto de esta polémica no es aleatoria, ya que en ella el autor retoma y amplía los mismos argumentos que habían utilizado y continuarían utilizando el resto de polemistas. Como ya comentábamos, la obra está precedida por un largo prólogo, dividido en veinte capítulos, el primero de los cuales lleva el siguiente título: «Con objetivo de divulgar la causa determinante de este escrito, tráese a colación la carta 16 del libro 7 , incluida por el deán de Alicante Manuel Martí en el tomo dos de sus Epístolas». Líneas más abajo declara que la finalidad del libro es «aniquilar, detener, aplastar y convertir en aire y humo la calumnia levantada a nuestra nación por el deán alicantino» (Eguiara, 1994, p. 54).

Vamos a acercarnos, como ya anunciábamos, al tratamiento que hace de los artículos de Feijoo, el «eruditísimo y muy autorizado crítico» (Eguiara, 1986, p. 134), así como de otros 'rastros' ilustrados que aparecen, para ver cuál es el enfoque que se les da.

El tratamiento de Feijoo es muy significativo. Ya en el primer prólogo presenta la Bibliotheca como un arma para luchar contra los «prejuicios y engañosas apreciaciones» (Eguiara, 1994, p. 59) de la epístola martiana, colocándose Eguiara, en cierto modo, como el destructor de errores vulgares en América. Sin embargo, a la hora de comentar el artículo de Feijoo sobre el ingenio de los americanos, aunque comienza diciendo que se va a corroborar la opinión del asturiano, Eguiara acepta tan solo su negativa a que el intelecto de los indianos decaiga antes que el de los peninsulares. Sin embargo, contradice al asturiano cuando concluye que en México los niños son realmente más inteligentes y que, por lo tanto, la afirmación de Feijoo a este respecto es otro más de los errores vulgares, y si Eguiara se retracta al final es sólo, nos dice, porque no quiere ser acusado de soberbia:

Según Feijoo, el aprovechamiento anticipado de los nuestros no debe atribuirse a la anticipación de su capacidad, sino solo a la anticipación del estudio y continua aplicación a él. [...] Pero hemos de confesar ingenuamente la dificultad con que pasaremos a creer que los padres y protectores europeos se ocupen menos que los americanos de la formación literaria de sus hijos [...] Si los niños europeos van mucho más tardíamente a la escuela que los nuestros, es porque sus padres temen perder el tiempo haciéndolos estudiar en una edad que consideran inadecuada para la asimilación de los rudimentos primeros (Eguiara, 1994, p. 111).

El origen de esta divergencia está en la base de la argumentación. Feijoo parte de la 
falsedad de la teoría climática de raíz aristotélica: la razón está repartida por igual en todas las latitudes y el mayor o menor desarrollo de una determinada región se debe exclusivamente a circunstancias coyunturales y materiales que han ido variando a lo largo de la historia, tal como explicara en su «Mapa intelectual...». Eguiara, por contra, no pone en cuestión la teoría climática-siguiendo en esto la actitud de sus predecesores en la polémica contra Martí- ni discute su trasfondo científico o filosófico sino que se limita a desplazar, o mejor dicho, a invertir los términos: el clima americano era el más propicio al desarrollo de las cualidades morales e intelectuales y había sido otro de tantos dones con los que la divinidad ha bendecido las tierras americanas ${ }^{5}$. De hecho, unas páginas antes, en el prólogo XI titulado «Del ingenio de los americanos y de su amor y afición a las letras», había defendido este argumento con abundantes autoridades:

D. Juan de Cárdenas, insigne por análogas dotes y calidades, tiene por evidente y fuera de toda duda que los españoles nacidos en América sobresalen por su ingenio agudo, delicado y vivo, explicando largamente las causas y principios naturales de este hecho. Enrique Martín [...] atribuye a la naturaleza del clima, del sol y del suelo americanos, no solo la mayor vivacidad de ingenio de los naturales de estas partes, sino también el hecho de que los nacidos en otros países se hagan más dispuestos e ingeniosos cuando habitan las regiones mexicanas o se trasladan a las del Perú. [...] Y para no hacernos interminables, cierre esta enumeración de autores [...] Jerónimo Pérez de Nueros que [...] se expresa así: [...] «¿Quién negará que, merced a estos tres factores [el clima, el sol y el suelo], este amenisimo lugar de la tierra, favorecido por la bendición de Dios y por una temperatura siempre deliciosa, ha agotado los principales tesoros del riquisimo venero de la omnipotencia divina?" (Eguiara, 1994, p. 104-107).

Como vemos, no solo afirma y 'prueba' lo que Feijoo negaba -aunque en el texto evita habilidosamente la confrontación- sino que, además, el procedimiento que sigue para defender la veracidad de estos hechos es el recurso escolástico al testimonio de autoridades, evidentemente en las antípodas del experimentalismo feijooniano. En otras palabras, incluso cuando se refiere a la defensa que Feijoo realiza del ingenio americano, ni apoya sus teorías ni utiliza su método.
Pero no es este el único lugar en el que contradice a Feijoo. Aunque en los prólogos se muestra conciliador con las críticas del benedictino al método escolástico y se limita a puntualizar que el estudio de la filosofía en las universidades americanas no es «anárquico ni decadente, sino cuidado y bien atendido» (Torre, 1986, p. CXLVII), sí lo hizo en otros lugares uniéndose él también a la polémica entre Feijoo y los defensores del método escolástico. Recordemos en este sentido la carta que dirigió en 1759 a Francisco Ignacio Cigala, que este incluyó en los preliminares de su Carta al Ilmo. y Rmo. P. Benito Gerónimo Feijoo [...] que escribió Francisco Antonio Cigala Americano y que fue publicada en la propia imprenta de Eguiara. En ella alaba la defensa de la filosofía escolástica practicada por Cigala frente a los ataques de Feijoo, gracias a la cual, de paso, se defiende las universidades peninsulares y americanas en las que se practica:

Pero aún es digno de mayores gracias el estudio de Vnd., como empleado en vindicar el honor de las Universidades Españolas, así Europeas como Americanas, [...] y juzgo tan acreedor a la gratitud de las Escuelas, como apreciable el respeto debido a sus profesores, a sus alumnos, y a sus aulas, que todos y todas se desairan, desairando a la Philosophia Aristotélica, la cual les hace el fondo, y principalmente a la Theología llamada por antonomasia Escolástica (citado por Torre, 1986, p. CXLVI).

En este marco ideológico es en el que hay que entender las otras menciones a corrientes más o menos modernas que en los prólogos demuestra conocer. Estas se limitan básicamente a aquellas relacionadas con un criticismo moderado que en ningún caso ponía en duda los tres ejes básicos interdependientes: los dogmas católicos, la filosofía escolástica y la fidelidad a la corona. Se trataría, por ejemplo, de la crítica histórica maurina o las corrientes filosóficas gassendista y cartesiana, todas nacidas en el siglo anterior y que él coloca como las más novedosas. Además, cuando habla de ellas y de su cultivo en Nueva España destaca -y esto es lo más significativo- que el conocimiento de su existencia no ha supuesto ningún cambio en la ortodoxia escolástica:
Feijoo y la Ilustración en una polémica novohispana del siglo XVIII: ¿Es Eguiara y Eguren un escolástico ilustrado?

CLAUDIA COMES PEÑA 


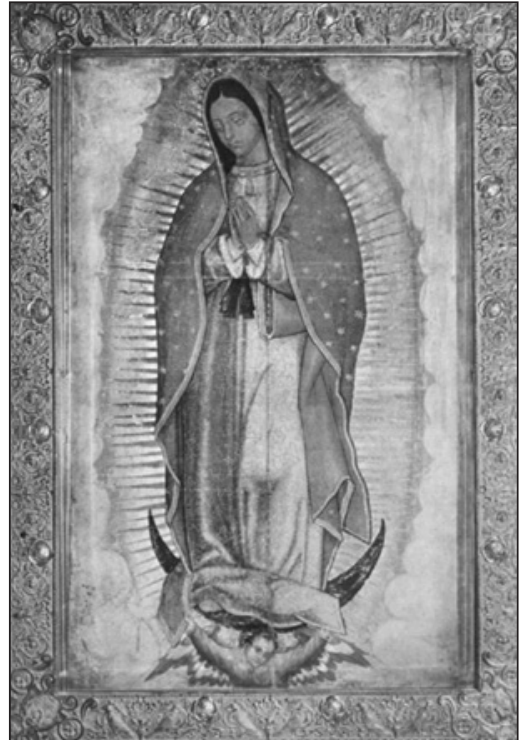

Imagen de la Virgen de Guadalupe

6

No podemos dejar de mencionar, aunque sea en nota al pie la tentación que ha sido para los que hemos trabajado con la traducción de Millares Carlo ver una prueba fehaciente de la presencia ilustrada en el uso reitera do del adjetivo ilustrado para caracterizar el tipo de saber característico, entre otros, de los antiguos mexicanos. Sin embargo, si acudimos al texto origina comprobamos que este término aparece sistemáticamente como traducción del latino eruditus, por lo que refleja más bien e pensamiento del traductor que el del propio Eguiara y Eguren. Efectivamente, se toma para ello su acepción genérica y preilu strada según la cual ilustrado es, efectivamente, sinónimo de instruido, erudito (Álvarez, 1992 p. 183 y ss.).

Feijoo y la Ilustración en un polémica novohispana del siglo XVIII: ¿Es Eguiara y Eguren un escolástico ilustrado?

CLAUDIA COMES PEÑA
Aunque muchos no sólo han desflorado, sino penetrado a fondo y divulgado en sus escritos la gandesiana y cartesiana y otras que fuera de España se cultivan por muchos sabios, no por eso se han separado de la de nuestros mayores y de la peripatética (Eguiara, 1994, p. 191).

Es decir, Eguiara saca pecho y presume de que en la América española no se ha abandonado el escolasticismo ni se han variado los sistemas filosóficos a pesar de la llegada hasta ellos de las nuevas corrientes de pensamiento.

Algo muy similar ocurre cuando menciona publicaciones periódicas relacionadas con la Ilustración, el Acta eroditorum de Leipzig y el Diario de los literatos de España. Para empezar, se trata de dos revistas que, aunque fueron altavoces de cierto reformismo, nunca perdieron su inequívoco carácter cristiano y moderado ${ }^{6}$. Además, se refiere a ellas tan solo para explicar que en las dos aparecen críticas a la obra de Martí, un argumento ad hominem para, indirectamente, reforzar el rechazo de sus afirmaciones sobre los americanos.

¿Qué nos indican estos datos? En lo que atañe a la presencia de las nuevas corrientes en Nueva España, nos muestran que se puede constatar su presencia pero no así su asimilación o su defensa por parte de las élites universitarias. Además, en lo que a ellos respecta -me refiero a Eguiara y el resto de polemistas-, se preocupan por distanciarse de la base filosófica en la que se asientan estas y hacen un uso un tanto peculiar de ellas. En el caso de Eguiara, aunque sea insistir en lo evidente, podemos afirmar con Mario Góngora que nunca fue militante en las filas de la Ilustración, ni siquiera de esa moderada, divulgativa y ya expurgada que llegaba de la Metrópoli y que, de hecho, entre los detractores de las ideas ilustradas «el más importante de ellos fue, sin duda, el bibliógrafo Juan José Eguiara, quien sutilmente señaló que, un cambio en la filosofía introduce imperceptiblemente cambios en la teología» (1998, p. 184).

Esto nos lleva de lleno a la caracterización del saber defendido y practicado en la universidad novohispana $y$, por extensión, por una buena parte de la intelectualidad novohispana. A pesar de que algunos críticos han incluido a Eguiara en la nómina de una «primera ilustra- ción mexicana» (Trabulse, 1983), lo expuesto aquí nos hace dudar de esta filiación. Como ha señalado Emilio Reyes, «conscientes de que el predominio de la temporalidad va en detrimento de la creencia en la divinidad, conventos, colegios y universidades fueron una fortaleza dentro de la Nueva España. La defendían de un enemigo: el tiempo, o su forma más concreta, la llegada de la modernidad» (2011, p. 23). Tal como se desprende de los estudios de Bernabé Navarro, «la filosofía en la que piensan y razonan los hombres [de la colonia] nunca deja de ser escolástica, aun en la última etapa, donde hay una seria transformación por influjo de la filosofía moderna» (1964, p. 11).

Dicho esto, parece que nos encontremos ante una contradicción. Eguiara rechaza sin ambigüedades la filosofía moderna pero, al mismo tiempo, se preocupa de demostrar su conocimiento. ¿Con qué finalidad, si no es la de darlos a conocer, hace uso de estos autores y corrientes en su Bibliotheca Mexicana? Para llegar a la respuesta debemos recorrer el camino del plano intertextual y el juego de citas explícitas e implícitas que supone todo escrito polémico. Los anteloquia se presentan ante el lector explícitamente como respuesta a la epístola del deán alicantino. Pero, ¿a quién está respondiendo realmente? A lo largo de los prólogos nos encontramos con la referencia de más autores que defendieron las mismas ideas que Martí sobre la inferioridad cultural y moral americana. Además, Eguiara hace mucho hincapié en las teorías climáticas que ya hemos comentado, aspecto al que el de Alicante no hace ni la más mínima referencia. ¿Por qué, entonces, se reprende de esa manera a Martí? La elección del alicantino como "cabeza de turco» no es casual. Precisamente el carácter tópico de su escrito, su total falta de originalidad y reflexión propia sobre el tema americano, lo convertían en el resumen perfecto a través del cual poder combatir los prejuicios europeos. Si a ello sumamos que era un humanista de prestigio en ese momento -cosa que Eguiara no se cansa de repetir-, que nunca había pisado suelo americano y que, por lo tanto, hablaba de oídas, se nos abren muchas puertas sobre los mecanismos argumentativos del mexicano.

Para empezar, no debemos olvidar cuál es el objetivo primordial del texto en el que se inserta, que no es otro que la vindicación de las capacidades intelectuales de los americanos 
y, por extensión, el replanteamiento no solo de su propia definición como españoles nacidos en América, sino la de la propia América española en su conjunto. Este proceso tenía la finalidad última de crear «vías para construir sus propios espacios de poder y legitimación socio-cultural frente a una situación en la que se les limitaba [a los criollos] las posibilidades de acceso dentro de los aparatos de gobierno virreinal» (Higgins, 1996, p. 77)

La abundancia de citas bibliográficas desempeñan un papel fundamental en la defensa. Si bien por una parte se pueden interpretar como una rémora del argumento de autoridad escolástico, aquí también son utilizados como demostración de que a Nueva España, frente a lo que muchos como el deán de Alicante afirmaban, llegaban las noticias de la cultura europea. El fin último sería, por tanto, demostrar que los habitantes americanos se podían medir en condición de igualdad con los europeos en cuanto a conocimientos (Gil, 2010), aunque no se adhirieran ideológicamente a las nuevas corrientes.

De hecho, para Eguiara incluso estarían en una posición ventajosa, ya que además de dominar los códigos culturales europeos, dominan también los americanos, cosa de la que no podían presumir los peninsulares, tal como se esfuerza en demostrar a lo largo de los prólogos y cuyo ejemplo paradigmático sería el propio Martí. En una segunda lectura este juego de citas que remiten constantemente al saber de los criollos, conforman no sólo la defensa sino también el armazón del nuevo modelo cultural americano. Las «autoridades» a las que se da voz en los anteloquia, tanto en lo que atañe al saber prehispánico como al de la América colonial, son siempre personajes nacidos en el nuevo continente o que han pasado una muy larga temporada en sus tierras, personas que conocen directamente la realidad sobre la que escriben. Con esta forma de acaparar el dominio de la realidad se colocan claramente en un nivel superior al de los peninsulares que nunca cruzaron el Atlántico, y se erigen como los intermediarios imprescindibles para acceder a ese saber.

Llegados a este punto, y retomando las disquisiciones iniciales, se podría discutir largamente sobre si esta postura se puede considerar un germen independentista, como han afirmado algunos estudiosos. Para Torre Villar, por ejemplo,
[...] el proyecto nacional tan completo que tiene la generación de criollos de la primera mitad del siglo XVIII es un proyecto que maduró a través de dos centurias. Era un proyecto que cristalizaba pacíficamente, racional y plenamente justificado. Los criollos percibieron que existían los elementos que configuran una nación: pueblo, territorio y valores comunes. Estos elementos que son los que de acuerdo con el derecho público se requieren para que se consolide una nación, estaban plenamente integrados, lo cual debería permitir la constitución de un estado independiente (1986, p. 149).

A mi modo de ver, a estas alturas del siglo la emergente conciencia diferenciada en las élites criollas aún mantiene el vínculo entre monarquía y religión entendidas como una sola unidad y sólo reclaman una cuota de poder dentro del sistema mayor que era el Imperio. Sólo décadas más tarde, cuando la monarquía española ya no esté en situación de proporcionar estabilidad institucional, se recurrirá a los discursos identitarios como justificación de acciones políticas. En el caso de Eguiara sería más conveniente hablar de la creación de una identidad cultural que de una identidad nacional.

Todo esto nos lleva a ver con un poco más de claridad el complejo entramado ideológico de Nueva España a mediados del siglo XVIII. Eguiara, evidentemente, estaba muy lejos de ser un ilustrado, pero es un eslabón muy importante para comprender la especificidad del pensamiento dieciochesco novohispano y de las direcciones específicas que tomó a partir de sus circunstancias propias.

\section{Bibliografía}

Álvarez de Miranda, Pedro (1992), Palabras e ideas: el léxico de la Ilustración temprana en España (1680-1760), Madrid, RAE.

Arciniegas, Germán (1956), «La Ilustración en Hispanoamérica», Mélanges à la memoire de Jean Serrailh, París, Centre de Recherches de Institut d'Études Hispaniques.

Chiaramonte, José Carlos (1979), Pensamiento de la Ilustración. Economía y sociedad americanas en el siglo XVIII, Caracas, Ayacucho.

Cruz, Salvador (1966), «Feijoo en México. Notas de asedio", en El padre Feijoo y su siglo, Oviedo, Cátedra Feijoó, pp. 47-54.

Darnton, Robert (2003), George Washington's false teeth: an unconventional guide to the eighteenth century, New York, Norton.
Feijoo y la Ilustración en una polémica novohispana del siglo XVIII: ¿Es Eguiara y Eguren un escolástico ilustrado?

CLAUDIA COMES PEÑA 
Eguiara y Eguren, Juan José (1986), Bibliotheca Mexicana, México, Ex nova Typographia in Aedibus Authoris editioni, 1755, vol. I (A-C); edición moderna con prólogo y versión española de Benjamín Fernández de valenzuela, estudio preliminar, notas, apéndices y coordinación de Ernesto de la Torre Villar, México, Fondo de Cultura Económica, 5 vols.

Feijoo, Benito Jerónimo (1775), «Españoles americanos», en Teatro crítico universal (1726-1740), tomo cuarto (1730). Texto tomado de la edición de Madrid 1775 (por D. Blar Morán, a costa de la Real Compañía de Impresores y Libreros), tomo cuarto (nueva impresión, en la cual van puestas las adiciones del Suplemento en sus lugares), pp. 109-125.

Feijoo, Benito Jerónimo (1779), «Mapa intelectual, y cotejo de Naciones», en Teatro crítico universal, tomo segundo (1728). Texto tomado de la edición de Madrid 1779 (por D. Joaquín Ibarra, a costa de la Real Compañía de Impresores y Libreros), tomo segundo (nueva impresión, en la cual van puestas las adiciones del Suplemento en sus lugares), pp. 299-321.

García Cárcel, Ricardo (1992), La leyenda negra. Historia y opinión, Madrid, Alianza.

Gerbi, Antonello (1982), La disputa del Nuevo Mundo, México, FCE.

Gil Amate, Virginia (2010), « Confiar en los criollos? Apreciaciones sobre la condición de los españoles americanos en el siglo XVIII», Olivar no 14, pp. 13-31.

Góngora, Mario (1998), Estudios sobre la bistoria colonial de Hispanoamérica, Santiago de Chile, Editorial Universitaria.

Higgins, Anthony (1996), «La Biblioteca Mexicana: hacia una poética de la legitimidad cirolla», Revista de Crítica Literaria Latinoamericana (Berkley), no 22, pp. 77-87.

López, François (1979), «Ilustración e independencia hispanoamericana», en $\mathrm{Ho}^{-}$ menaje a Noël Salomon, Barcelona, Universidad Autónoma de Barcelona, pp. 289-297.

Maravall, José Antonio (1991), Estudios de la bistoria del pensamiento español (siglo XVIII), Introd. y compilación de Mari Carmen Iglesias, Madrid, Mondadori.

Feijoo y la Ilustración en una polémica novohispana del siglo XVIII: ¿Es Eguiara y Eguren un escolástico ilustrado?

CLAUDIA COMES PEÑA traducción de las citas que aparecen aquí es mía.

Millares Carlo, Agustín (1944), «Feijoo en América», Cuadernos americanos, $\mathrm{n}^{\circ} 3$, pp. 139-160.

Millares Carlo, Agustín (ed.) (1994), Prólogos a la Biblioteca Mexicana, México, FCE.

Navarro, Bernabé (1964), Cultura mexicana moderna en el siglo XVIII, México, UNAM.

O'Gorman, Edmundo (1942), Fundamentos de la historia de América, México, Imprenta Universitaria.

Osorio Romero, Ignacio (1989), Conquistar el eco. La paradoja de la conciencia criolla, México, UNAM.

Palacio Atard, Vicente (1966), «La influencia del P. Feijoo en américa», en El padre Feijoo y su siglo, Oviedo, Cátedra Feijoó, pp. 21-32.

Reyes Ruiz, Emilio (2011), «El pensamiento filosófico en la Ciudad de México durante la colonia: una muralla contra el tiempo», Multidisciplinaria. Revista electrónica de la Facultad de Estudios Superiores Acatlán, $\mathrm{n}^{\circ}$ 3, pp. 23-36.

Rovira, José Carlos (1995), «Para una revisión de la polémica mexicana dieciochesca con Manuel Martí, deán de Alicante», en Entre dos culturas. Voces de identidad bispanoamericana, Alicante, Universidad de Alicante, pp. 45-62.

Rovira, José Carlos (1999), Varia de persecuciones en el XVIII novohispano, Milán, Bulzoni.

San José Vázquez, Eduardo (2006), «Ilustración e independencia hispanoamericana: una polémica historiográfica y literaria», Cuadernos de Ilustración y Romanticismo, no 14, pp. 283-299.

Sánchez-Blanco, Francisco (1991), Europa y el pensamiento español del siglo XVIII, Madrid, Alianza.

Soto Arango, Diana; Puig-Samper, Miguel Ángel y Arboleda, Luis Carlos (eds.) (1995), La Ilustración en América Colonial, Madrid, Doce calles.

Trabulse, Elías, Historia de la ciencia en México, México, Conacyt-FCE, 1983.

Fecha de recepción: 26/04/2013

Fecha de aceptación: 29/07/2013 